\title{
CONDUCTAS ASOCIATIVAS CONSTITUCIONALMENTE PROTEGIDAS EN MÉXICO*
}

\author{
ASSOCIATIVE INTERNAL DESITIONS CONSTITUTIONALLY \\ PROTECTED IN MEXICO
}

\section{José Juan ANZURES GURRÍA**}

RESUMEN: El derecho fundamental de asociación, constitucionalmente reconocido en el artículo 9o. de la Constitución Política de los Estados Unidos Mexicanos, comprende bajo su halo de protección a la misma asociación que nace del ejercicio individual del derecho. En este sentido, la asociación tiene la facultad de organizarse libremente sin interferencia alguna por parte de terceros, en particular de la autoridad estatal. Toda asociación es libre de nacer a la vida jurídica y existir, de tener personalidad jurídica, de dotarse de sus estatutos, a decidir sobre el ingreso, expulsión y sanción de sus miembros, y, por último dejar de existir.

Palabras clave: Derecho de asociación, autoorganización, estatutos, acuerdos asociativos
ABSTRACT: The constitutional right of asembly is recognized in art. 9 of the Mexican Constitution and it includes, not only the individual right to get together, but also the association itself. Thereby the association has the capacity to organize itself without any interference from others, in particular from the State. Every association has the right to born and exist, to have legal personality, to establishes their statutes, to decide about the admission, expulsion and punishment of its members, and finally to dissolve itself.

Keyzerds: Freedom of association, self organization, statutes, internal decisions.

* Artículo recibido el 19 de marzo de 2016 y aceptado para su publicación el 25 de agosto de 2016.

** Doctor en Derecho por la Universidad de Navarra. Miembro del SNI, nivel I. Director del Departamento de Derecho del Instituto Tecnológico y de Estudios Superiores de Monterrey, campus Puebla.

Boletín Mexicano de Derecho Comparado nueva serie, año XLX, núm. 148, enero-abril de 2017, pp. 15-48.

D. R. (C) 2017. UNAM, Instituto de Investigaciones Jurídicas. 
Esta revista forma parte del acervo de la Biblioteca Jurídica Virtual del Instituto de Investigaciones Jurídicas de la UNAM

SUMARIO: I. Introducción. II. Las conductas asociativas protegidas por el artículo 9o., CPEUM. III. El derecho de la asociación a dejar de existir. IV. Conclusiones. V. Bibliografia.

\section{INTRODUCGIÓN}

El derecho fundamental de asociación, consagrado en el artículo 9o. de la Constitución Política de los Estados Unidos Mexicanos (en adelante CPEUM), comprende bajo su halo de protección, además de la libertad para crear asociaciones, a la misma asociación que nace del ejercicio individual del derecho. Desde el momento en que se crea una asociación, ésta nace con vida propia e independiente, y la facultad que tiene para desenvolverse y funcionar libremente como un sujeto nuevo y distinto de las personas que la han creado ${ }^{1}$ se encuentra constitucionalmente protegida, y es que, como ha señalado en España A. J. Gómez Montoro, de nada serviría garantizar el derecho de crear asociaciones si una vez creadas quedaran al albur del poder público. ${ }^{2}$

A este ámbito de protección que el derecho fundamental de asociación dispensa a la misma asociación se le ha denominado principalmente en Alemania y recientemente en España como la dimensión colectiva del derecho de asociación, en oposición a la dimensión individual. La dimensión colectiva del derecho de asociación no debe confundirse con el ejercicio colectivo del derecho fundamental de asociación. Este último se refiere a la forma en que se realiza el derecho de asociación, que es de manera colectiva, pues aunque se trate de un derecho individual, su ejercicio se realiza de manera conjunta con otras personas, pues es lógico que nadie puede asociarse solo o consigo mismo. En este sentido, en Alemania se ha señalado que el acto de creación de una asociación implica no sólo la creación de la asociación en sí misma, sino todos las demás decisiones previas necesarias para que dicha creación pueda llevarse a cabo y que se deciden también colectivamente, tales como el nombre, el fin, la sede y, sobre todo, los estatutos de la asociación.

1 Lucas Murillo del Cueva, E., Igualdad y autonomía. Las competencias sobre asociaciones en la jurisprudencia constituciónal, Madrid, Civitas, 1999, p. 83.

2 Gómez Montoro, A. J., Asociación, Constitución, ley. Sobre el contenido constitucional del derecho de asociación, Madrid, CEPC, 2004, p. 173. 
Esta revista forma parte del acervo de la Biblioteca Jurídica Virtual del Instituto de Investigaciones Jurídicas de la UNAM

En nuestro país, J. Barrera Graf distingue dos fases en el momento de creación de una sociedad mercantil, que al fin y al cabo es una asociación; en la primera fase el autor inserta las convergencias y divergencias (de los futuros socios) en torno al proyecto de sociedad con la adopción de acuerdos provisionales para alcanzar la agrupación en torno a la figura de sociedad que desean crear; si bien el autor no lo señala expresamente, estas convergencias y divergencias bien podrían referirse a las decisiones sobre el nombre, el fin, la sede, y en general a todo el contenido estatutario; la segunda fase se refiere al contrato preliminar de sociedad, que surge con motivo de las negociaciones, y que es el epígrafe del contrato definitivo que habrá de ser otorgado ante el fedatario público. ${ }^{3}$ Lo que queda claro es que el acto de creación de estas asociaciones, como el de todas, requiere de la concurrencia de las voluntades de las otras personas con las que se pretende uno asociar.

Sin embargo, la dimensión colectiva del derecho de asociación no se refiere al ejercicio colectivo del acto creacional de una asociación, con todas las convergencias y divergencias que dicho acto comprende, sino más bien a la protección constitucional que se dispensa a la asociación misma una vez creada, siendo ella, y ya no los socios individualmente considerados, la titular del derecho de asociación.

\section{LAS CONDUCTAS ASOCIATIVAS PROTEGIDAS POR EL ARTÍCULO 9o., CPEUM}

Las asociaciones, cualesquiera que éstas sean y sin importar su fin, nacen del ejercicio individual del derecho fundamental de asociación, y han de estar protegidas por el mismo amparo que dispensa el artículo 9o. CPEUM. Pero no todas las conductas de una asociación se en encuentran protegidas por este artículo constitucional; si así fuera se iusfundamentalizaría toda la conducta de la asociación. ${ }^{4}$

Distinguir qué conductas asociativas se encuentran protegidas por el halo que dispensa la dimensión colectiva del derecho de asociación de aquellas que no lo están, es una tarea no sólo necesaria, sino además com-

3 Barrera Graf, J., Instituciones de derecho mercantil (generalidades, derecho de la empresa, sociedades), México, Porrúa, 2000, pp. 318 y 319.

4 Gómez Montoro, A. J., Asociación, Constitución, ley, cit., p. 190. 
Esta revista forma parte del acervo de la Biblioteca Jurídica Virtual del Instituto de Investigaciones Jurídicas de la UNAM www.juridicas.unam.mx

DOI: http://dx.doi.org/10.22201/iij.24484873e.2017.148.10994

plicada. En aras de dar una respuesta a esta cuestión, la jurisprudencia y la doctrina alemanas han diferenciado entre las actividades asociativas internas y externas, donde las primeras son aquellas que encuentran su protección en la libertad asociativa, y las segundas no. ${ }^{5}$ Sin ánimo de entrar en la discusión dogmática que se ha llevado a cabo en Alemania, podemos decir junto con A. J. Gómez Montoro, ${ }^{6}$ que el argumento diferenciador entre unas conductas y otras tiene que ver con la mera organización de la asociación; es decir, cuando las conductas asociativas se refieran a cuestiones de organización interna del ente serán actividades internas, actividades protegidas por el derecho de asociación. ${ }^{7}$

Así, muchos de los derechos o facultades que las asociaciones pueden realizar libremente son actividades externas, actividades que si bien tienen como finalidad la consecución de su fin - toda actividad asociativa persigue el fin de la asociación - no se encuentran protegidos por el derecho fundamental de asociación porque no se refieren a la autoorganización de la asociación, por lo que encontrarán su protección en los derechos de los que la asociación, como persona jurídica, es titular, ya sean derechos fundamentales o de naturaleza iusprivatista, ${ }^{8}$ pero no en el derecho fundamental de asociación. Por ejemplo, el derecho constitucional que tienen los partidos políticos para acceder a los medios de comunicación (artículo 41, base III, CPEUM), es un derecho constitucional reconocido a estos entes por su determinado tipo y porque es necesario para la consecución de sus fines, pero no es un derecho que pueda incardinarse en el derecho

\footnotetext{
5 Merten, D., Vereinsfreiheit, cit., p. 1071.

6 Gómez Montoro, A. J., Asociación, Constitución, ley..., cit., p. 192.

7 Véase en Alemania H. D. Jarass, "Art. 9o., Vereinigungs- und Koalitionfreiheit”, en
} Jarass H. D. y Pieroth, B., Grundgesetz für die Bundesrepublik Deutschland, Kommentar, München, Verlag C. H. Beck, 2007, p. 272; Hesse, K., Grundzüge des Verfassungsrechts der Bundesrepublik Deutschland, Heildelberg, C. F. Müller, 1999, pp. 160 y 161; Schnorr, G., Öffentliches Vereinsrecht, Kommentar zum Vereinsgesetz, Verlag, 1965, p. 40. También Gastroph, C., Die politischen Vereinigungen. Inhalt und Grenzen der Vereinigungsfreiheit des Art. 9 des Grundgesetzes im politischen Bereich in der Verfassungsstruktur der Bundesrepublik Deutschland, Berlin, Dunker \& Humblot, 1970, p. 65; Scholz, R., Koalitionsfreiheit als Verfassungsproblem, München, Beck, 1971, pp. 140 y 141. Del Tribunal Constitucional Federal alemán véase por todas su sentencia $B \operatorname{VerfGE}$ 70, 1, 25, del 14 de mayo de 1985. En España véase la STC 24/1987. En Estados Unidos véase la sentencia Roberts v. United States Yacees, 468 U.S. 609, 619 (1984).

8 Sobre la titularidad de los derechos fundamentales por personas jurídicas véase Gómez Montoro, A. J., "La titularidad de derechos fundamentales por personas jurídicas: un intento de fundamentación", REDC, año 22, núm. 65, 2002, pp. 49-106. 
Esta revista forma parte del acervo de la Biblioteca Jurídica Virtual del Instituto de Investigaciones Jurídicas de la UNAM

de asociación, sino que se trata de la titularidad de la libertad de expresión que tienen los partidos políticos para alcanzar sus fines, pero no del derecho de asociación que protege la facultad de autoorganización del partido. ${ }^{9}$ Lo mismo ocurre con los demás actos que, en tanto persona jurídica, una asociación puede celebrar, como contratos de compraventa, de arrendamiento, de permuta, etcétera, son actos que no se encuentran constitucionalmente protegidos por el derecho fundamental de asociación. Dicho en pocas palabras, lo único que protege el derecho fundamental de asociación hacia las mismas asociaciones es su capacidad para autoorganizarse sin interferencia alguna por parte de terceros.

En el ámbito sindical, M. de la Cueva distingue también entre las actividades internas y las externas; si bien no señala que unas se encuentran protegidas por el derecho de asociación y otras no, la distinción coincide con la concepción que se ofrece aquí. Para este autor, las actividades externas de un sindicato son la celebración y revisión de los contratos colectivos y de los contratos-ley, el reglamento interior de trabajo, así como la integración de los organismos desde los cuales el sindicato operará en defensa y para el amejoramiento de las condiciones de vida de la clase trabajadora, como puede ser el caso de las juntas de conciliación y arbitraje. ${ }^{10}$ Estas conductas externas son conductas que el sindicato realiza para la consecución de sus fines (el estudio, mejoramiento y defensa de los intereses del trabajo), y si se prohibieran por parte de la autoridad se estaría vulnerando la libertad sindical, mas no la libertad de asociación, porque ésta se materializa en la medida en que la asociación - el sindicato- puede autoorganizarse libremente.

Ahora, que las asociaciones tengan la libertad de autoorganizarse libremente no significa que este derecho de autoorganización se ejerza de manera absoluta o sin observar algún límite; por el contrario, el ejercicio del derecho de asociación sólo es posible en y a través del ordenamiento jurídico. ${ }^{11}$ En efecto, al adoptar sus distintos acuerdos de autoorganización, la asociación deberá observar tanto sus estatutos como la legislación que las regule, dependiendo del tipo de asociativo en cuestión, y es evi-

9 Véase la jurisprudencia de rubro "PARTIDOS POLÍTICOS. SUS DERECHOS CONSTITUCIONALES RELACIONADOS CON EL ACCESO A LOS MEDIOS DE COMUNICACIÓN SOCIAL", D]; 10a. Época; Pleno; S. F. F. y su Gaceta; libro IV, enero de 2012, tomo 1; pág. 425.

10 Cueva, M. de la, El nuevo derecho mexicano del trabajo, cit., p. 289.

11 Gómez Montoro, A. J., Asociación, Constitución, ley, cit. p. 76. 
Esta revista forma parte del acervo de la Biblioteca Jurídica Virtual del Instituto de Investigaciones Jurídicas de la UNAM

dente que la asociación que se acoja a un determinado tipo legal verá restringida en cierta forma su capacidad de autodeterminación por las disposiciones que dicha norma contenga, lo que no puede entenderse como una intromisión en el ámbito constitucionalmente protegido por éste, sino simplemente como una labor de configuración de cada tipo asociativo por parte del legislador. ${ }^{12}$

En este sentido, nuestra SCJN reconoció en su sentencia del 17 de marzo de 2004, que

...corresponde al legislador, ya sea federal o local, establecer en la ley relativa la forma en que se organizarán los ciudadanos en materia política, conforme a criterios de razonabilidad que permitan el pleno ejercicio de ese derecho fundamental, así como el cumplimiento de los fines que persiguen los partidos políticos.

Si bien en esta sentencia la SCJN se refiere a los requisitos para constituir un partido político, el razonamiento resulta extensible a la organización de todas las asociaciones, y resulta lógico que dependiendo del tipo asociativo el legislador determine distintos requisitos de organización. ${ }^{13}$ En términos parecidos se expresó otra vez la SGJN en la ya cita-

\footnotetext{
12 Idem.

13 Partidos políticos. Corresponde al LEGISLAdor ESTABlecer lOS REQUiSITOS PARA SU CREACIÓN, CON APEGO A LAS NORMAS CONSTITUCIONALES CORRESPONDIENTES Y CONFORME A CRITERIOS DE RAZONABILIDAD QUE PERMITAN EL PLENO EJERCICIO DEL DERECHO DE ASOCIACIÓN EN MATERIA POLÍTICA. El artículo 41 de la Constitución Política de los Estados Unidos Mexicanos garantiza la existencia de los partidos políticos, mas no establece cuáles son los elementos de organización a partir de los cuales deben crearse, por lo que en este aspecto existe una delegación al legislador sujeta a criterios de razonabilidad guiados por el propósito de que dichas entidades de interés público cumplan con los fines que prevé dicho precepto, esto es, que sean el medio para promover la participación del pueblo en la vida democrática, que contribuyan a la integración de la representación nacional y que hagan posible el acceso de los ciudadanos al ejercicio del poder público. Por otro lado, los artículos 9o. y 35, fracción III, de la Constitución Federal, que prevén la garantía de libre asociación en materia política para los ciudadanos de la República, no señalan la forma concreta de organización en que debe ejercerse ese derecho, por lo que, de acuerdo con lo previsto en el artículo 41 constitucional, corresponde al legislador regular tal aspecto, con los límites ya descritos. Por tanto, de una interpretación armónica de lo dispuesto por los artículos 9o., 35, fracción III y 41, fracción I, de la Ley Fundamental, se concluye que la libertad de asociación, tratándose de partidos políticos, no es absoluta, sino que está afectada por una característica de rango constitucional, conforme a la cual su participación en los procesos electorales queda sujeta
} 
Esta revista forma parte del acervo de la Biblioteca Jurídica Virtual del Instituto de Investigaciones Jurídicas de la UNAM

da resolución 58/2010, en la que señaló que los artículos 216, párrafo segundo; 221, fracción IV, párrafo tercero, y 238, fracción III, incisos c) y d), de la Ley de Instituciones y Procedimientos Electorales del Estado de Baja California, no transgredían las garantías institucionales de autoorganización y autodetermianción de los partidos políticos reconocidas en el artículo 41, CPEUM, porque no afectan la vida interna de dichos institutos, pues tales prescripciones no les impiden llevar a cabo el proceso de designación de candidatos, ya sea por la vía de selección interna o directamente, en términos de la propia legislación, de sus estatutos, lineamientos y acuerdos. ${ }^{14}$

a lo que disponga la ley ordinaria, esto es, corresponde al legislador, ya sea federal o local, establecer en la ley relativa la forma en que se organizarán los ciudadanos en materia política, conforme a criterios de razonabilidad que permitan el pleno ejercicio de ese derecho fundamental, así como el cumplimiento de los fines que persiguen los partidos políticos". Acción de inconstitucionalidad 6/2004 y su acumulada 9/2004. Partido del Trabajo y la Agrupación Política Nacional denominada "Movimiento Nacional de Organización Ciudadana". 16 de marzo de 2004. Mayoría de ocho votos. Ausente: Humberto Román Palacios. Disidentes: Genaro David Góngora Pimentel y José de Jesús Gudiño Pelayo. Ponente: Juan Díaz Romero. Secretarios: Pedro Alberto Nava Malagón y Laura García Velasco. Novena Epoca, Instancia: Pleno, Fuente: Semanario Fudicial de la Federación y su Gaceta, tomo: XIX, junio de 2004, p. 867.

14 [J; 9a. Época; Pleno; S. F. F. y su Gaceta; tomo XXXI, abril de 2010; pág. 1567. INSTITUCIONES Y PROCEDIMIENTOS ELEGTORALES DEL ESTADO DE BAJA CALIFORNIA. LOS ARTÍCULOS 216, PÁRRAFO SEGUNDO, 221, FRACGIÓN IV, PÁRRAFO TERCERO Y 238, FRACGIÓN III, INCISOS G) Y D), DE LA LEY RELATIVA, AL CONDICIONAR LAS PRECAMPAÑAS A LA EXISTENCIA DE DOS O MÁS PREGANDIDATOS, NO TRANSGREDEN LAS GARANTÍAS INSTITUCIONALES DE AUTO-ORGANIZAGIÓN Y AUTO-DETERMINAGIÓN DE LOS PARTIDOS POLÍTICOS, NI EL PRINCIPIO DE EQUIDAD EN LA CONTIENDA. Los artículos 41, base I, párrafo tercero y 116, fracción IV, inciso f), de la Constitución Política de los Estados Unidos Mexicanos prevén las garantías institucionales de auto-organización y autodeterminación de los partidos políticos, en virtud de las cuales las autoridades sólo pueden intervenir en la vida interna de dichos institutos en los términos establecidos por el propio Ordenamiento Fundamental y las leyes, así como el principio de equidad en la contienda, conforme al cual se garantiza que las condiciones materiales y jurídicas en la contienda electoral no favorezcan a alguno de los participantes. En ese sentido, los artículos 216, párrafo segundo, 221, fracción IV, párrafo tercero y 238, fracción III, incisos c) y d), de la Ley de Instituciones y Procedimientos Electorales del Estado de Baja California, al condicionar la autorización que corresponde otorgar a los partidos políticos a sus militantes o simpatizantes para realizar actos de precampaña, a que existan dos o más precandidatos en una contienda interna, e impedir directamente a los precandidatos realizar actividades proselitistas o de propaganda en la fase de precampaña cuando sean designados en forma directa sin que medie proceso de selección interna, previendo como sanción en caso de in- 
Esta revista forma parte del acervo de la Biblioteca Jurídica Virtual del Instituto de Investigaciones Jurídicas de la UNAM

En pocas palabras, la ley puede imponer una determinada estructura a las asociaciones limitando en parte su autonomía organizacional, pero estas limitaciones deberán estar justificadas y ser proporcionales, evitando que se pueda llegar a sofocar por completo la libertad de autoorganización de la asociación, pues ello implicaría la vulneración del contenido esencial del derecho de asociación y en consecuencia la eliminación del mismo. Ahora, las normas que regulan los distintos tipos asociativos sólo son vinculantes para las asociaciones que quieran constituirse como tales, y, en consecuencia regularse por dichas normas. Las asociaciones pueden no observar los mandatos que determine la ley, lo que no significa que la asociación sea ilegal o inconstitucional, sino simplemente que no se encontrará regulada por esa determinada ley. Por ejemplo, si una agrupación política nacional no observa los mandatos establecidos por la Ley General de Partidos Políticos para convertirse en tal será una asociación con fines políticos, pero no un partido político.

\section{El "derecho" de la asociación a existir}

La facultad de autoorganización de la asociación se concreta, según ha reconocido la jurisprudencia constitucional alemana, en el derecho de la misma asociación a existir y funcionar (recht auf enstehen und bestehen) sin

cumplimiento de esta prohibición la pérdida del derecho a registrar como candidato al precandidato, no transgreden las referidas garantías institucionales ni el indicado principio. Lo anterior es así, por lo que hace a las garantías, porque no afectan la vida interna de dichos institutos, dado que tales prescripciones no les impiden llevar a cabo el proceso de designación de candidatos, ya sea por la vía de selección interna o directamente, en términos de la propia legislación, de sus estatutos, lineamientos y acuerdos; y, por cuanto hace al principio de equidad, porque todos los que se ubiquen en ese supuesto están sujetos a la misma regulación y dado que permitir actos de propaganda en la fase de precampaña, cuando no se requiere alcanzar la nominación de candidato, sería inequitativo para los precandidatos de los demás partidos que deben someterse a un proceso democrático de selección interna y obtener el voto necesario para ser postulados candidatos, ya que esa propaganda puede generar una difusión de su imagen previamente a la fase de campaña, generando inequidad en la contienda frente a los demás precandidatos que lleguen a postularse". Pleno. Acción de inconstitucionalidad 85/2009. Partido Político Convergencia. 11 de febrero de 2010. Once votos. Ponente: Juan N. Silva Meza. Secretario: José Francisco Castellanos Madrazo. El Tribunal Pleno, el doce de abril en curso, aprobó, con el número 58/2010, la tesis jurisprudencial que antecede. México, Distrito Federal, a doce de abril de dos mil diez. 
Esta revista forma parte del acervo de la Biblioteca Jurídica Virtual del Instituto de Investigaciones Jurídicas de la UNAM www.juridicas.unam.mx

interferencia alguna por parte del Estado. A decir verdad, el derecho a existir es un derecho de la asociación una vez que ya se ha constituido, pues por estricta lógica una asociación que todavía no existe no puede tener derecho a existir. En este sentido, el derecho a existir por primera vez, o si se quiere el "derecho" de la asociación a nacer, es un derecho de los socios fundadores a que la asociación por ellos creada sea reconocida como tal por el derecho; aunque también es cierto que una vez constituida la asociación, ésta tiene el derecho, de igual forma, a ser reconocida por el ordenamiento jurídico. El determinar el momento en que la asociación se considera existente o nacida resulta de gran importancia, porque desde ese momento se encontrará constitucionalmente protegida en lo que a sus actividades internas se refiere.

El momento en el que una asociación ha nacido para el mundo del derecho suele variar según el tipo asociativo del que se trate. Así, el texto original de la Ley General de Sociedades Mercantiles (en adelante LGSM) consideraba necesario que una sociedad mercantil se registrara en el Registro de Comercio, pero para ello era necesario de una orden judicial, que se otorgaba una vez que en un procedimiento de jurisdicción voluntaria, con audiencia del agente del Ministerio Público, se comprobara la conformidad del clausulado de la escritura y los estatutos con la normatividad vigente. Una vez agotadas las etapas del procedimiento, y de encontrar plenamente apegado a derecho el contenido de la escritura constitutiva, el juez ordenaba al Registro Público que llevara a cabo la inscripción de la sociedad naciente, sin cuyo requisito no sería obsequiada. Este procedimiento pretendía que la autoridad judicial llevara a cabo una revisión del contenido de la escritura constitutiva con la intención de verificar su conformidad con la normatividad vigente, destacando el cumplimiento de los requisitos que mínimamente se establecen por la LGSM, y que no contuviera vicios de ilegalidad, ilicitud o trasgresión a la normatividad de orden público, en cuyo caso la inscripción sería denegada en la sentencia que al efecto se emitiera. Con la reforma del 11 de junio de 1992 el procedimiento de juicio voluntario quedó derogado, correspondiendo sólo al fedatario público la revisión y adecuación del contenido estatutario a la normatividad vigente, así como el trámite relativo a su inscripción ante el registro público. ${ }^{15}$

15 Véase artículo 5o., LGSM.

D. R. (C) 2017. UNAM, Instituto de Investigaciones Jurídicas, Boletín Mexicano de Derecho Comparado, núm. 148, pp. 15-48. 
Esta revista forma parte del acervo de la Biblioteca Jurídica Virtual del Instituto de Investigaciones Jurídicas de la UNAM

Actualmente la Ley de Sociedades Mercantiles prevé que la sociedad puede fundarse en un solo acto por convenio entre los fundadores o en forma sucesiva por suscripción pública de las acciones; en ambos casos será necesario el cumplimiento de las formalidades legales. ${ }^{16}$ Para que pueda llevarse a cabo la constitución de la sociedad mercantil ante fedatario público y su inscripción ante el registro mercantil, es preciso que cuente con la autorización que le otorga el Estado a través de la Secretaría de Relaciones Exteriores.

No obstante lo anterior, en el caso de las sociedades mercantiles, éstas pueden no inscribirse en el registro público, o incluso no otorgar su acto constitutivo ante fedatario público, lo que trae consigo que dichas asociaciones sean consideradas sociedades irregulares o de hecho, y ello no significa que carezcan de personalidad jurídica. En este sentido J. Barrera Graf considera que tanto las sociedades regulares como las sociedades irregulares tienen personalidad jurídica, y que la única diferencia es que la personalidad que corresponde a las sociedades regulares se adquiere por virtud de su inscripción en el registro de comercio y es de pleno derecho, mientras que la personalidad de las sociedades irregulares se adquiere en virtud de actos celebrados con terceros. ${ }^{17}$ La inscripción registral no tiene entonces carácter constitutivo ni tampoco de otorgamiento de la personalidad jurídica para las sociedades mercantiles, ni mucho menos para las sociedades civiles, pues a éstas no se les exige su inscripción.

En el ámbito de los sindicatos, el artículo 357 de la Ley Federal del Trabajo (en adelante LFT) señala que los trabajadores y los patrones tienen el derecho de constituir sindicatos sin necesidad de autorización previa, y que cualquier injerencia indebida será sancionada en los términos que disponga la ley, ${ }^{18}$ lo que denota la intención del legislador por beneficiar la libertad sindical sin injerencia alguna por parte de la autoridad. Es más, el artículo 366 de LFT dispone que el registro de un sindicato podrá negarse únicamente si no se propone el estudio, mejoramiento y defensa de los intereses del trabajo, si no se dispone del número de miembros exigidos por ley y si no se exhiben los documentos necesarios. Pero en caso de que se negara el registro de una asociación que pretende adquirir la

16 Sánchez Calero, F., Instituciones del derecho mercantil, 14a. ed., Madrid, Revista de Derecho Privado, 1990, p. 197.

17 Ibidem, pp. 125 y 126.

18 Reforma del 30 de noviembre de 2012. 
Esta revista forma parte del acervo de la Biblioteca Jurídica Virtual del Instituto de Investigaciones Jurídicas de la UNAM

calidad de sindicato por la falta de alguno de estos requisitos no significa que la asociación deje de existir, quizá no obtendrá la calidad de sindicato o la personalidad jurídica de sindicato, pero sin duda es una asociación que existe y se desenvuelve en el tráfico jurídico; no será un sindicato, pero sí una asociación de otra índole; ${ }^{19}$ aunque ciertamente no podrá alcanzar los mismos fines ni obtener los beneficios que la ley otorga a estos tipos de asociaciones.

Por lo demás, en el ámbito de los sindicatos, el acto de inscripción registral tampoco es necesario para conceder la personalidad jurídica, a diferencia del sistema francés, en el que el depósito de los estatutos otorga la personalidad jurídica a los solos efectos de publicidad. En México, señala M. de la Cueva, la personalidad jurídica de los sindicatos nace con su constitución, de tal forma que el registro de estos entes es un elemento que sirve para autenticar la existencia del sujeto de derechos y obligaciones. ${ }^{20}$ La inscripción es, pues, un acto declarativo mediante el cual se da fe de que el sindicato quedó constituido, pero de ninguna manera tiene efectos constitutivos.

En general, somos de la opinión de que el Registro público no tiene efectos constitutivos para las asociaciones - para ninguna- y tampoco concede personalidad jurídica general, concede la personalidad jurídica deseada según el tipo asociativo, la de un tipo asociativo concreto, la personalidad de partido político, la de sindicato o la de sociedad mercantil, pero desde el momento en que una asociación se constituye mediante el acuerdo de voluntad de las partes tiene personalidad jurídica, no la del tipo deseado, pero al fin y al cabo personalidad. Desde una perspectiva iusfundamental, que es la que ahora nos ocupa, no podemos entender que una asociación, cualquiera que sea su tipo, no exista hasta que no se inscriba en el Registro público; si así fuera, se estaría dejando desprotegida a la asociación durante un periodo de tiempo que de facto ya existe. Por esto, entendemos que la postura más favorecedora hacia el derecho fundamental de asociación es aquella que considera que la asociación nace con el simple acuerdo de voluntad de las partes, mismo que le otorga personalidad jurídica, y que desde ese mismo momento se encuentra constitucionalmente protegida en cuanto a sus actividades internas se refiere.

\footnotetext{
19 Cueva, M. de la, El nuevo derecho mexicano del trabajo, cit., p. 332.

20 Ibidem, p. 349.
} 
Esta revista forma parte del acervo de la Biblioteca Jurídica Virtual del Instituto de Investigaciones Jurídicas de la UNAM

\section{El derecho de la asociación a funcionar}

Desde el momento en que una asociación nace, se encuentra constitucionalmente protegida en cuanto a sus actividades de autoorganización se refiere. Estas actividades suelen encuadrarse principalmente en dos conductas concretas: en la facultad para adoptar libremente sus estatutos y en la libertad para adoptar sus acuerdos, ${ }^{21}$ siempre y cuando estos últimos se refieran a cuestiones de autoorganización y sean consecuentes con sus estatutos.

\section{A. Libertad de la asociación para darse sus estatutos}

En el ejercicio de su autonomía organizativa, la asociación tiene la facultad para darse a sí misma sus propios estatutos. ${ }^{22}$ En los estatutos, dice E. Lucas Murillo, es donde se plasma la medida del ejercicio de autonomía de la asociación, ${ }^{23}$ en ellos, la asociación determina su estructura interna, su desenvolvimiento, ${ }^{24}$ su funcionamiento, sus actividades en el exterior y la forma de alcanzar sus fines. Los estatutos son la expresión de la voluntad de la asociación y en el fondo la voluntad de los socios, ${ }^{25}$ pues determinan las relaciones entre ellos mismos y con la asociación de la que forman parte. Además, los socios aprueban los estatutos bajo las cuales se regirán, ya sea desde el momento fundacional de la asociación o bien al incorporarse en el grupo ya constituido, y tienen carácter vinculante para ellos, ${ }^{26}$ porque si no fuera así, sería imposible la vida de las agrupaciones humanas. ${ }^{27}$

21 A. Pace ha denominado "autonomía normativa y organizativa". "Comentario al art. 18 CI”, en Branca, G. (dir.), Comentario della Constituzione. Art. 13-20, Bolonia-Roma, 1977 , pp. 191 y ss.

22 Anzures Gurría, J. J., La protección constitucional de las asociaciones. Sobre la dimensión colectiva del derecho de asociación, Madrid, CEPCM, 2014, pp. 223 y ss.

23 Lucas Murillo de la Cueva, E., El derecho de asociación, cit., p. 224.

24 Ferrara, F., Teoría de las personas jurídicas, Granada, Comares, 2006, p. 725.

25 Bermejo Vera, J., "La dimensión constitucional del derecho de asociación", R. A. P., núm. 136, 1995, p. 140.

26 Se trata de un pactum associationis.

27 Cueva, M. de la, El nuevo derecho mexicano del trabajo, cit., p. 353. 
Esta revista forma parte del acervo de la Biblioteca Jurídica Virtual del Instituto de Investigaciones Jurídicas de la UNAM

Sin embargo, aunque la asociación es libre de determinar el contenido de sus estatutos, éstos se verán limitados por la Constitución ${ }^{28}$ y las leyes, tanto por aquellas reguladoras de cada tipo asociativo ${ }^{29}$ como por las normas penales o de cualquier otro tipo que regule de algún modo a las asociaciones. Así, las sociedades civiles deberán observar lo dispuesto en los artículos 2688 y siguientes del Código Civil; los partidos políticos deberán observar lo dispuesto por la Ley General de Partidos Políticos; los sindicatos deberán observar lo establecido por la Ley Federal del Trabajo, y lo que todas estas normas dispongan no implica la violación por parte del legislador de la autonomía estatutaria de las asociaciones. En este sentido, nuestra SCJN reconoció en su jurisprudencia 142/2005 que las disposiciones contenidas en los artículos 56, fracciones II, III y V, y 56 bis, de la Ley Electoral del Estado de Jalisco, que preveía ciertos requisitos que los estatutos debían contener, no representaba intromisión alguna en la vida interna de los partidos, pues la finalidad prevista por la Constitución Política de los Estados Unidos Mexicanos para estos entes, consistente en la promoción de los principios democráticos, incluye que éstos deben regir en su interior, pues sólo así permanecen en estrecha comunicación con sus miembros, con lo que se cumplirá el objetivo de permitir que los partidos sean organizaciones de ciudadanos que hagan posible su acceso al poder público, y en tal virtud, es necesario que sus estatutos prevean un funcionamiento democrático verdadero, asegurando que cuenten con estructuras y prácticas de participación que tengan el control de sus líderes y la colaboración de sus afiliados en la formación de estos liderazgos; de no existir elementos de certeza en cuanto a los procedimientos internos y

\section{Idem.}

29 ATC 2/1993, del 11 de enero, FJ 1o: “el primer límite intrínseco del derecho fundamental de asociación lo marca el principio de legalidad en el ejercicio de la potestad para proveerse de normas propias y, en tal sentido, los Estatutos han de acomodarse no sólo a la Constitución sino también a las leyes que, respetando el contenido esencial de tal derecho, lo desarrollen o lo regulen". Véase la sentencia del Tribunal Electoral del Poder Judicial de la Federación de rubro "EsTATUTOS DE UN PARTIDO POLÍtico O DE UNA COALICIÓN. HIPÓTESIS DE IMPUGNACIÓN". Tercera Época: Recurso de apelación. SUPRAP-036/99. - Miguel Ángel Garza Vázquez. - 16 de febrero de 2000.— Unanimidad de votos. Recurso de apelación. SUP-RAP-003/2000 y acumulados.-Coalición Alianza por el Cambio. - 16 de febrero de 2000. - Unanimidad de votos. juicio para la protección de los derechos político-electorales del ciudadano. SUP-JDC-039/2000 y acumulado.Ana Cristina Enríquez Miér. - 17 de mayo de 2000.- Unanimidad de votos. Sala Superior, tesis S3ELJ 55/2002. 


\section{de transparencia en el funcionamiento de los partidos, así como el estable- cimiento de garantías para sus afiliados, estos entes no cumplirían con la función que tienen constitucionalmente asignada. ${ }^{30}$}

30 []; 9a. Época; Pleno; S. F. F. y su Gaceta; tomo XXII, noviembre de 2005; pág. 154. PARTIDOS POlíticos ESTATALES. LOS ARTíCulos 56, FRAGCIONES II, III Y V, Y 56 BIS DE LA LEy Electoral del ESTADO DE JALISGO, AL PREVER CIERTOS REQUiSITOS QUE DEBEN CONTENER LOS ESTATUTOS DE AQUÉLLOS, SON CONSTITUCIONALES. Los citados artículos prevén la obligación de los partidos políticos de incorporar en sus estatutos, el primero, los procedimientos de afiliación individual, libre y pacífica de sus miembros, quienes tendrán el derecho de participar en asambleas y convenciones, de integrar los órganos directivos y estar en condiciones de acceder a la información pública del partido (fracción II); procedimientos democráticos de elección de candidatos a cargos de elección popular y de sus órganos directivos, así como la enumeración de sus funciones, facultades y obligaciones, las que deben ser del conocimiento público (fracción III); así como prever sanciones fundadas y motivadas, impuestas por órganos competentes previamente establecidos y que deben ser proporcionales a la infracción cometida (fracción V); y el segundo, el procedimiento claro para la elección de dirigentes en todos los niveles de organización, y garantizar la certeza, legalidad, independencia, imparcialidad, equidad, objetividad, transparencia y certidumbre: previendo periodos fijos para la duración y renovación de mandos internos y procedimientos para la sustitución de ellos, y estableciendo reglas generales de la elección de los dirigentes y los requisitos mínimos. Ahora bien, los aspectos antes mencionados no representan una intromisión indebida en la vida interna de los partidos, pues la finalidad prevista por la Constitución Política de los Estados Unidos Mexicanos para los partidos políticos, consistente en la promoción de los principios democráticos incluye que éstos deben regir en su interior, pues sólo así permanecen en estrecha comunicación con sus miembros, con lo que se cumplirá el objetivo de permitir que los partidos sean organizaciones de ciudadanos que hagan posible su acceso al poder público; en tal virtud, es necesario que sus estatutos prevean un funcionamiento democrático verdadero, asegurando que cuenten con estructuras y prácticas de participación que tengan el control de sus líderes y la colaboración de sus afiliados en la formación de estos liderazgos, pues de no existir elementos de certeza en cuanto a sus procedimientos internos y de transparencia en su funcionamiento, así como el establecimiento de garantías para sus afiliados, no cumplirían con la función que constitucionalmente tienen asignada. Por otra parte, el hecho de que artículo 56 bis disponga que, además de lo previsto en el indicado artículo 56, los estatutos deben establecer un procedimiento claro para la elección de los dirigentes en todos los niveles de organización y que, para garantizar la certeza, legalidad, independencia, imparcialidad, equidad, objetividad, transparencia y certidumbre, deben prever reglas respecto de los periodos de duración y renovación de sus mandos internos, así como procedimientos de sustitución de dirigentes electos, aparte de establecer reglas generales para su elección, es una cuestión que tampoco constituye una intromisión en la vida interna de los partidos políticos, por las razones previamente señaladas, en atención a que debe garantizarse la promoción del pueblo en la vida democrática de manera efectiva, y que no se dé lugar a la creación de cúpulas en las que siempre recaigan las decisiones y las candidaturas a cargos de elección popular, puesto que tal situación sí sería contraria al espíritu del artículo 41, fracción I, de la Constitución de la República”. Pleno. Acción de 
Esta revista forma parte del acervo de la Biblioteca Jurídica Virtual del Instituto de Investigaciones Jurídicas de la UNAM

Sin embargo, el hecho de que las asociaciones deban observar en sus estatutos lo establecido por las leyes que las rigen no implica que las asociaciones no puedan contemplar otras cuestiones. Las asociaciones pueden, en el ejercicio de su autonomía organizativa constitucionalmente protegida, determinar cualquier otra cuestión que consideren prudente en aras de alcanzar sus fines. Entendemos que las distintas leyes reguladoras de los distintos fenómenos asociativos son leyes de mínimos y si una asociación observa estos mínimos, nada le impide contemplar cualquier otro extremo. En este sentido, el artículo 371 LFT, señala que los requisitos establecidos para los estatutos no contienen una enumeración limitativa, y señala en su fracción final que podrán agregarse "las demás normas que apruebe la asamblea".

Por lo demás, los estatutos de una asociación han de ser respetuosos con los derechos humanos, sin que puedan contemplar la renuncia a su titularidad por parte de los socios. Es cierto que la libertad de autorregulación de las asociaciones puede comprender la renuncia por parte de los socios al ejercicio - que no a la titularidad - de algunos de sus derechos, y ha de reconocerse que en el ejercicio de su libertad los socios pueden asumir voluntariamente limitaciones al ejercicio de algunos de sus derechos en aras de alcanzar otros intereses. ${ }^{31}$ Pero esta renuncia por parte de los socios al ejercicio de algunos de sus derechos sólo será válida cuando no afecte su integridad física ni moral, ni se incurra en alguna conducta delictiva y siempre y cuando quienes hayan asumido voluntariamente tales restricciones a sus derechos recobren por su sola decisión la integridad de sus derechos abandonando la asociación. ${ }^{32}$

Existen, de todas formas, algunos derechos cuyo ejercicio resulta irrenunciable, como es el caso de los derechos de la personalidad, el derecho a la vida, la integridad personal y el acceso a los tribunales. ${ }^{33}$

inconstitucionalidad 13/2005. Partido del Trabajo. 22 de agosto de 2005. Unanimidad de diez votos. Ausente: Guillermo I. Ortiz Mayagoitia. Ponente: Genaro David Góngora Pimentel. Secretarios: Makawi Staines Díaz y Marat Paredes Montiel. El Tribunal Pleno, el dieciocho de octubre en curso, aprobó, con el número 142/2005, la tesis jurisprudencial que antecede. México, Distrito Federal, a dieciocho de octubre de dos mil cinco.

31 Es posible, por ejemplo, que algunas personas decidan incorporarse a una disciplina muy rigurosa en la que su libertad quede limitada y su conducta sometida la voluntad de otros. Lucas Murillo de la Gueva E., El derecho de asociación, cit., pp. 166-168 .

32 Ibidem, pp. 167 y 168.

33 Ibidem, p. 228. 
Esta revista forma parte del acervo de la Biblioteca Jurídica Virtual del Instituto de Investigaciones Jurídicas de la UNAM www.juridicas.unam.mx

\section{B. La libertad de la asociación para adoptar libremente sus acuerdos de autoorganización}

Hemos dicho que los acuerdos de autoorganización adoptados por la asociación en el uso de su autonomía son manifestación del derecho fundamental de asociación, ${ }^{34}$ pero sólo aquellos — hemos de insistir - que versen sobre la organización y el funcionamiento interno de la asociación, aquellos que tienen que ver con su estructura interna, la gestión de sus asuntos, el cambio de sus fines, su régimen sancionador, la incorporación de nuevos socios y la expulsión de miembros. ${ }^{35}$ Algunos autores señalan que en los acuerdos asociativos se plasma el ámbito real de ejercicio de la libertad de autoorganización, ${ }^{36}$ pero nosotros no lo entendemos así, ya que su validez depende de su concordancia con sus mismos estatutos; ${ }^{37}$ por tanto, la asociación, o, mejor dicho, los órganos de la asociación, no son completamente libres de adoptar sus acuerdos, sino que es en realidad al configurar los estatutos y determinar la ampliación de las facultades de los órganos asociativos donde se materializa la autonomía organizativa de la asociación constitucionalmente protegida.

a. Los acuerdos asociativos respecto de la estructura orgánica de la asociación

En el ejercicio de su autonomía organizativa, la asociación es libre de adoptar los acuerdos asociativos correspondientes a su estructura orgánica. La organización pertenece a la naturaleza misma de los entes colectivos, que no son un amontonamiento de personas, sino una unión para la realización de fines permanentes y que trascienden la vida de quienes lo formaron. ${ }^{38} \mathrm{Si}$ bien estas cuestiones se plasman en las distintas leyes reguladoras de cada tipo asociativo, en tanto se trata de actividades de au-

34 Marín López, J. J., "La intervención judicial en los conflictos endoasociativos: el caso de la expulsión de asociados", Poder fudicial, núm. 14, 1989, p. 154.

35 Gómez Montoro, A. J., Asociación, Constitución, ley..., cit., p. 193. Véase también Anzures Gurría, J. J., La protección constitucional de las asociaciones... cit. p. 249.

36 Lucas Murillo de la Cueva, E., Igualdad y autonomía, cit., p. 129; también en El derecho de asociación, cit., pp. 182-192.

37 Lucas Murillo de la Cueva, E., El derecho de asociación, cit., p. 218.

38 Cueva, M. de la, El nuevo derecho mexicano del trabajo..., cit., p. 286. 
Esta revista forma parte del acervo de la Biblioteca Jurídica Virtual del Instituto de Investigaciones Jurídicas de la UNAM

toorganización, y por tanto constitucionalmente protegidas, entendemos que, entre otras, estas actividades se refieren a la facultad de la asociación para determinar lo siguiente: $a$ ) los tipos de órganos, su denominación y su número; $b$ ) la composición de los órganos asociativos y la forma de elegir a sus miembros, y c) el funcionamiento interno de cada órgano.

\section{b. Los acuerdos asociativos para decidir sobre el ingreso de nuevos miembros}

En el ejercicio de su autonomía organizativa, la asociación es libre de escoger a las personas que van a formar parte de ella. ${ }^{39}$ Esta libertad comprende, por un lado, la facultad de la asociación para determinar los requisitos necesarios que una persona ha de satisfacer para convertirse en socio, lo que suele plasmarse en sus estatutos, y por otro lado, la facultad de la asociación para adoptar el acuerdo propiamente dicho de admisión o rechazo de una persona. ${ }^{40}$.

La determinación por parte de la asociación de los requisitos que las personas han de satisfacer para ser miembros garantiza la homogeneidad interna de las asociaciones y al mismo tiempo la diversidad externa de éstas, lo que resulta necesario en una sociedad democrática y plural, para que los ciudadanos se dirijan a aquellas asociaciones que mejor satisfagan sus distintas necesidades, y, en caso de que no exista ninguna que las satisfagan a la perfección, las personas son libres para crear su propia asociación que persiga los fines que pretendan y de la forma que consideren conveniente. ${ }^{41}$

Esta facultad de la asociación para decidir el ingreso de nuevos socios suele ser un aspecto no poco controvertido, ya que muchas veces el acuer-

39 Bilbao Ubillos, J. V., Libertad de asociación y derechos de los socios..., cit., p. 26. Según este autor, los acuerdos asociativos mediante los cuales las asociaciones deciden el ingreso o no de nuevos miembros en su seno constituyen una manifestación del ejercicio de su autonomía, de esa esfera insuprimible reducto de vida auténticamente privada, que queda fuera del alcance de las normas constitucionales, en el que las asociaciones son libres a la hora de seleccionar a las personas con las que van a relacionarse también. "Prohibición de discriminación y autonomía privada", Los alardes, cit,. p. 102; este mismo autor dice que "la libertad individual puede ejercerse de forma irracional o incongruente".

40 Anzures Gurría, J. J., La protección constitucional de las asociaciones..., cit., pp. 334 y ss.

41 Alfaro Águila-Real, J., "Libertad e igualdad en el derecho de asociación", Los alardes, cit., p. 131 
Esta revista forma parte del acervo de la Biblioteca Jurídica Virtual del Instituto de Investigaciones Jurídicas de la UNAM

do asociativo, sobre todo el que niega el ingreso de un solicitante a socio, suele colisionar con el derecho de ingreso a una determinada asociación que tiene toda persona, derecho que también forma parte del ámbito protegido por el derecho fundamental de asociación, pero en su dimensión individual. ${ }^{42}$ Debe aclararse que en realidad, el derecho de ingresar a una asociación ya constituida es un derecho oponible frente al Poder Público y no frente a la asociación a la que se pretende ingresar; esto significa que el Estado no puede impedir a una persona ingresar a la asociación que desee, mas no que esta persona tenga un derecho subjetivo a ser admitida por la asociación de la que quiere formar parte, ${ }^{43}$ mientras que los acuer-

42 En España no son pocos los casos que respecto de esta cuestión han llegado a los tribunales. En la STS 846/2007 del 13 de julio, el demandante alegó precisamente que el acuerdo de inadmisión de un club de golf al que pretendía entrar, vulneraba su derecho fundamental de asociación, en tanto su derecho de ingreso, y solicitaba en consecuencia que se condenara a la asociación a que lo admitiera como socio. El Juzgado de Primera Instancia y la Audiencia Provincial que conocieron del caso consideraron que no existía obligación para la asociación de admitir en su seno a todo aquel que lo solicitara. Mientras que el Tribunal Supremo consideró además que el acuerdo mediante el cual se negó el ingreso a este solicitante no vulneró su derecho fundamental de asociación, toda vez que la decisión fue "ajustada a derecho", en tanto fue adoptada conforme a sus propios estatutos, que a su vez no contravenían las leyes ni la Constitución y se apoyó en una base "objetivamente razonable". Véase también la STS 708/2001 del 11 de julio.

43 En este sentido coincide la mayoría de la doctrina. Sauca Cano, J. M., señala que en todo caso, el derecho de ingreso se sujetará a las previsiones estatutarias preexistentes de la asociación, "Artículo 22 de la Constitución española", en Betegón Carrillo, J. et al. (coords.), Constitución y derechos fundamentales, 2004, p. 696. Desde una visión iusprivatista, concibiendo el acto de ingreso como un contrato privado, J. Alfaro Águila-Real señala que los particulares no tienen derecho a exigir de otro que contrate con ellos, ni siquiera si éste lo ha hecho con otras personas en idéntica situación. "Libertad e igualdad en el derecho de asociación", Los alardes..., cit., p. 129. Para S. Pérez Escalona, el derecho subjetivo de ingreso a la asociación sólo existirá si así lo dispone la ley. El derecho de asociación y las asociaciones en el sistema constitucional español, Pamplona, Aranzadi, 2007, p. 94. Véase también, Bilbao Ubillos, J. M., Libertad de asociación y derechos de los socios, cit., p. 22, y Gómez Montoro, A. J., Asociación, Constitución, ley..., cit., pp. 198 y 199. En México, refiriéndose a los sindicatos, M. de la Cueva señaló que si bien nada impide que un trabajador solicite su ingreso a determinado sindicato, esto no significa que exista un derecho al ingreso, pues si así fuera se limitaría el principio de libre sindicación de los demás trabajadores que ya forman del sindicato al obligarlos a asociarse con otro u otros en contra de su voluntad. El nuevo derecho mexicano del trabajo, cit., p. 353. En este mismo sentido, la SAP de Pontevedra, del 3 de junio de 1997 FJ2o., señaló que: "por mucha tutela jurisdiccional que brinde a los derechos y libertades fundamentales, no alcanza tal categoría el legítimo interés (de pertenecer a la asociación)".

D. R. (C) 2017. UNAM, Instituto de Investigaciones Jurídicas, Boletín Mexicano de Derecho Comparado, núm. 148, pp. 15-48. 
Esta revista forma parte del acervo de la Biblioteca Jurídica Virtual del Instituto de Investigaciones Jurídicas de la UNAM

dos que la asociación adopte respecto al ingreso o rechazo de una persona dentro de la asociación sí se encuentran protegidos por la dimensión colectiva del derecho de asociación y forman parte de las facultades de organización (actividades internas) de la asociación constitucionalmente protegidas.

Ahora, los acuerdos asociativos mediante los cuales la asociación puede negar el ingreso de una persona suele obedecer a dos circunstancias; la primera, que el solicitante no satisfaga los requisitos de ingreso establecidos por la asociación, en cuyo caso no podrá obligarse a la asociación a que acepte en sus filas a quien no cumple con los requisitos para formar parte de ella. ${ }^{44}$ Piénsese, por ejemplo, en una asociación de madres solteras que niega el ingreso a un hombre, o una asociación de italianos radicados en México que niega el ingreso a un alemán. La segunda hipótesis se da cuando el solicitante sí cumple con los requisitos de ingreso, pero aun así la asociación le niega su entrada; en este segundo supuesto creemos que la asociación no puede verse obligada tampoco a aceptar en su seno a todo aquel que lo solicite, ni siquiera satisfaciendo los requisitos de ingreso, y es que así como nadie puede verse forzado a ingresar a una asociación, las asociaciones tampoco pueden verse forzadas a aceptar en su seno a todo aquel que lo solicite. ${ }^{45} \mathrm{El}$ acto de ingreso en un ente es un acto que requiere la concurrencia de la voluntad del solicitante y de la asociación. ${ }^{46}$

Se ha señalado, además, que el acuerdo mediante el cual una asociación niega el ingreso a un solicitante suele vulnerar el derecho a la igualdad de éste. Al respecto, hemos de señalar, en primer lugar, que si bien

44 En la sentencia del Tribunal Supremo de España 708/2001 del 11 de julio, el recurrente alegaba que el acuerdo mediante el cual la "Agrupación Deportiva Stadium Casablanca" le negaba su ingreso como socio de número, vulneraba su derecho fundamental de asociación, en lo referente a su derecho de ingreso. Sin embargo, y como se desprendió de los hechos, el solicitante no cubrió con los requisitos de ingreso establecidos por la asociación en sus estatutos, por lo que el acuerdo asociativo de inadmisión fue adoptado en el ejercicio de la autonomía de la asociación y con base en su normativa, la cual era conforme con las leyes y la Constitución, por lo que el acuerdo de inadmisión fue constitucional, y por ningún motivo conculcador del derecho fundamental de asociación del solicitante.

45 Marín López, J. J., "El derecho de ingreso en las asociaciones", Los alardes: una perspectiva jurídica. Libertad e igualdad en las relaciones entre particulares, Irún, Casino de Irún, 2000, p. 22. Así lo entendió también la AP de Barcelona en su sentencia del 11 de diciembre de 1990, al señalar expresamente que "no hay obligación alguna de admitir en una asociación a todo aquel que lo solicite...".

46 Pérez Escalona, S., La asociación y el derecho de sociedades, cit., p. 209. 
Esta revista forma parte del acervo de la Biblioteca Jurídica Virtual del Instituto de Investigaciones Jurídicas de la UNAM

la Constitución mexicana reconoce el derecho de igualdad en su artículo 4o., éste lo hace en sentido de igualdad jurídica, igualdad ante la ley, y no en el sentido de la igualdad real, ${ }^{47} \mathrm{y}$ aunque la igualdad entre las personas sea un principio del Estado democrático y en su dimensión social tenga como función eliminar las desigualdades de hecho (políticas, económicas, sociales, culturales) para conseguir la igualdad real y efectiva entre individuos y grupos, lo cierto es que no puede exigirse plenamente en las relaciones particulares. ${ }^{48}$ Las asociaciones, en el ejercicio de su derecho de asociación, tienen el derecho de asociarse con quien consideren pertinente, sin que tengan la obligación de tratar a todos los solicitantes de manera igualitaria. ${ }^{49}$

En segundo lugar, el acuerdo asociativo de inadmisión de un solicitante a socio suele obedecer muchas veces a la naturaleza de la asociación, de tal forma que no se puede considerar un acto discriminatorio el hecho de que una asociación niegue el ingreso de una persona que no cumple con los requisitos de ingreso según el tipo de asociación del que se trata. ${ }^{50}$ Por el contrario, así es como las asociaciones cumplen su función social, mediante la agrupación de personas con ciertas características en común, como su ideología, su creencia religiosa, su sexo, su raza o su afición por algún objeto de colección, y así es como el individuo, en compañía de otros, desarrolla su personalidad. ${ }^{51}$ No puede considerarse discriminatoria la decisión del Club España (por poner sólo un ejemplo) de negar el ingreso a aquellos que no son españoles o no tengan ascendencia española; ni puede considerarse discriminatorio el rechazo de ingreso de un judío en una asociación católica, o viceversa.

En la sentencia 4/2006 del 16 de enero del Juzgado de Primera Instancia núm. 2 de Azpeitia, en España, la parte actora consideró que el procedimiento seguido por la asociación a la que deseaba entrar

47 Respecto al derecho a la igualdad en México véase Soberanes Díez, J. M., La igualdad y la desigualdad jurídicas, México, Porrúa, 2011.

48 Alfaro Águila-Real, J., "Libertad e igualdad en el derecho de asociación", Los alardes, cit., pp. 127 y 128

49 Marín López, J. J., "El derecho de ingreso en las asociaciones”, Los alardes, cit., p. 22.

50 La negativa de ingreso a las personas que no cumplen con los requisitos de admisión no supone una conducta discriminatoria por parte de las asociaciones. Marín López, J. J., El derecho de ingreso en las asociaciones, cit., pp. 22 y 23

51 Alfaro Águila-Real, J., “Libertad e igualdad en el derecho de asociación”, Los alardes, cit., p. 135.

D. R. (C) 2017. UNAM, Instituto de Investigaciones Jurídicas, Boletín Mexicano de Derecho Comparado, núm. 148, pp. 15-48. 
Esta revista forma parte del acervo de la Biblioteca Jurídica Virtual del Instituto de Investigaciones Jurídicas de la UNAM

(Sociedad Cultural Deportiva y Recreativa Arralde Txiki) para tomar la decisión de su inadmisión, fue discriminatoria, al no aceptársele como miembro por el hecho de ser mujer. Sin embargo, al revisar los hechos de este caso, el juzgado constató que tanto la forma como el fondo del procedimiento seguido para acordar la inadmisión de la solicitante no habían vulnerado el derecho de igualdad y a la no discriminación por razón de sexo de la solicitante, y sí hubo un requisito de ingreso que no fue satisfecho por la solicitante, que consistía en la presentación de su solicitud con dos avales. En consecuencia, el acuerdo de inadmisión de la asociación no puede considerarse conculcador del derecho de igualdad de la solicitante; por el contrario, en este caso se manifiesta con toda claridad el ejercicio pleno del derecho de autoorganización de la asociación, que con base en sus estatutos decidió libre y democráticamente, sin conculcar ningún derecho fundamental del solicitante, no admitir a éste por no haber satisfecho los requisitos de ingreso.

Independientemente de lo anterior, una limitante a la facultad de la asociación para negar el ingreso de nuevos socios en su seno se refiere a la posición monopolista o preponderante que tenga la asociación en el sector económico, político o social en el que se desenvuelva, pues si se cuenta con esta condición el rechazo de ingreso por parte de la asociación a un solicitante en concreto constituye, no la violación de su derecho de asociación, sino el impedimento de realizar la conducta o de ejercer el derecho de fondo que la asociación tiene por fin. En el caso de la albufera de Valencia, por ejemplo, el Tribunal Constitucional español determinó que la negativa de ingreso por parte de una asociación de pescadores a unas mujeres redundaba en la violación de la libertad de trabajo de éstas, pues ellas querían pescar en dicha zona, y la única forma de hacerlo era formando parte de dicha asociación, ya que ésta tenía en exclusiva la concesión administrativa para su explotación. ${ }^{52}$

En resumen, podemos decir que en el ejercicio de su autonomía la asociación tiene el derecho de asociarse con quien crea conveniente y establecer los requisitos de ingreso de nuevos miembros según la finalidad del ente y el tipo asociativo. Los acuerdos mediante los cuales se niegue el ingreso de alguna persona que no satisface los requisitos es-

52 STC 104/1999. Cfr. Anzures Gurría, J. J., La protección constitucional de las asociaciones..., cit., pp. 363 y ss. 
Esta revista forma parte del acervo de la Biblioteca Jurídica Virtual del Instituto de Investigaciones Jurídicas de la UNAM www.juridicas.unam.mx

tablecidos no constituye ninguna violación al derecho fundamental de asociación ni al de igualdad de los solicitantes; por el contrario, constituyen una manifestación del derecho de autoorganización constitucionalmente protegido por el halo que despliega el derecho fundamental de asociación.

c. Los acuerdos asociativos para sancionar a sus miembros

La asociación tiene también la libertad constitucionalmente protegida para sancionar a sus miembros ${ }^{53}$ y la tiene con la finalidad de mantener un cierto orden en su seno. ${ }^{54}$ La potestad sancionadora de la asociación se concreta por un lado en la legitimación para determinar en sus estatutos las conductas prohibidas y las sanciones correspondientes a dichas conductas, así como los procedimientos sancionatorios y las sanciones, las cuales pueden consistir, por mencionar algunas, en la imposición de multas, la suspensión por un tiempo de la condición de socio, la expulsión definitiva del socio de la asociación, entre otras.

Por otro lado, la potestad sancionadora de la asociación se refiere a la adopción del acuerdo sancionador cuando la conducta del socio se adecue a la conducta prohibida estatutariamente. Al adoptar la asociación los acuerdos sancionatorios, debe observar, al igual que cuando adopta cualquier otro acuerdo, sus estatutos, las leyes y la Constitución,${ }^{55}$ respetando siempre los derechos humanos de toda persona. Por esta razón, la imposición de sanciones suele y debe hacerse observando ciertos derechos o garantías de los socios.

En España ha proliferado la postura de que las asociaciones, al adoptar un acuerdo sancionador, han de observar las garantías del derecho

53 Ibidem, pp. 371 y ss.

54 El Tribunal Constitucional español señaló en su STC 218/1988, del 22 de noviembre, que el derecho de asociación que comprende la potestad de organización de la asociación, se extiende a regular en los estatutos las causas y procedimientos de la imposición de las sanciones

55 Recuérdese el ATC 213/1993, del 11 de enero, FJ 1o., que señaló que el primer límite intrínseco del derecho fundamental de asociación "lo marca el principio de legalidad en ejercicio de la potestad para proveerse de normas propias y, en tal sentido, los Estatutos han de acomodarse no solo a la Constitución sino también a las leyes que, respetando el contenido esencial de tal derecho, lo desarrollen o lo regulen”. 
Esta revista forma parte del acervo de la Biblioteca Jurídica Virtual del Instituto de Investigaciones Jurídicas de la UNAM

sancionador penal y administrativo contenidas en los artículos 24 y 25, $\mathrm{CE}$, toda vez que cuando los órganos asociativos ejercitan su potestad sancionadora tienen la posibilidad de restringir o limitar derechos o imponer sanciones pecuniarias, con parecida amplitud a como lo pueden hacer los órganos de gobierno de la administración de justicia; ${ }^{56}$ además de que estas garantías constituyen no sólo un conjunto de reglas jurídicas, con un contenido preciso, sino que consagran una serie de valores básicos, susceptibles de operar como principios generales del derecho sancionador en un Estado de derecho. ${ }^{57}$

En México, es común que las asociaciones prevean un régimen disciplinario interno, y aunque esto existe en el mundo fáctico, no se ha reconocido doctrinalmente, hasta donde sabemos, que la potestad sancionadora de las asociaciones deba verse limitada por las garantías del derecho sancionador y del debido proceso, lo que implicaría importar las garantías contenidas en los artículos 14, 15, 16 y 17, CPEUM, en lo que resultase aplicable a la potestad sancionadora asociativa. ${ }^{58}$

Sin embargo, una garantía que sin duda debe reconocerse dentro del ámbito asociativo es el principio de legalidad. Esto es, que la conducta sancionable esté claramente establecida en los estatutos de la asociación, y también que el acuerdo de expulsión sea adoptado de la manera establecida por los mismos estatutos de la asociación. En otras palabras, creemos que las asociaciones deben observar el principio nulla poena sine lege al momento de sancionar a sus miembros. ${ }^{59}$ Lo sostenido aquí no debe sorprender; el mismo artículo 2707, CG, señala que ningún socio puede ser excluido de la sociedad (civil) sino por el acuerdo unánime de los demás socios y por causa grave prevista en los estatutos; también en

56 En este sentido, es muy ilustrativa la SAP de Burgos del 25 de julio de 2002, que señaló que en el ejercicio de su potestad sancionadora los órganos asociativos están sujetos a las exigencias del derecho de tutela judicial efectiva, conforme al artículo 24 de la Constitución.

57 Bilbao Ubillos, J. M., "Las garantías de los artículos 24 y 25 de la Constitución en los procedimientos disciplinarios privados. Un análisis de su posible aplicación a las sanciones impuestas por los órganos de gobierno de las asociaciones", Derecho Privado y Constitución, núm. 9, 1996, cit., p. 47.

58 La eficacia horizontal de las garantías del derecho sancionador y del debido proceso judicial son objeto de otro trabajo.

59 La observancia del principio nulla poena sine lege en el ámbito asociativo fue defendido hace ya mucho tiempo por Nipperdey, H. C., Grundrechte und Privatrecht, cit., p. 28. 
Esta revista forma parte del acervo de la Biblioteca Jurídica Virtual del Instituto de Investigaciones Jurídicas de la UNAM www.juridicas.unam.mx

el ámbito sindical el artículo 37 1, fr. VII, LFT, inciso g), señala que la expulsión de un afiliado sólo podrá decretarse por los casos expresamente consignados en los estatutos, debidamente comprobados y exactamente aplicables al caso.

La tipicidad de las normas sancionadoras (lex praevia et certa) constituye un presupuesto de la seguridad jurídica imprescindible en las relaciones asociativas, y, consecuentemente, del libre ejercicio de los derechos del sancionado. ${ }^{60}$ La finalidad es que el socio sepa cuáles son las conductas prohibidas y cuál es la consecuencia de su actuación, y como dice $\mathrm{N}$. de Buen refiriéndose a los sindicatos, impedir que las directivas puedan abusar de la aplicación de sanciones. ${ }^{61}$ En efecto, lo que se pretende, exportando dichos requisitos a todo fenómeno asociativo, es evitar la arbitrariedad por parte de las asociaciones en el ejercicio de su potestad sancionadora.

Por esto, en su sentencia 1068/2000, del 7 de noviembre, el Tribunal Supremo de España declaró no haber lugar al recurso de casación formulado por la Federación Provincial de Entidades de la Construcción (Fedeco) contra la sentencia del 16 de octubre de 2003, dictada en grado de apelación por la Sección Primera de la Audiencia Provincial de Santa Cruz de Tenerife, pues el pronunciamiento favorable a declarar nulo el acuerdo de expulsión se sustentaba únicamente en el hecho probado y no controvertido en casación, de que la sanción impuesta no respondía a una conducta previamente establecida en los estatutos de la asociación, siendo así que la decisión de expulsarles, aunque se adoptó por el órgano que tenía la competencia para imponer dicha sanción, fue arbitraria y carente de base razonable que la justificara, privando a los socios de la posibilidad de saber que ese comportamiento estaba prohibido.

Pero la observancia del principio de legalidad por parte de las asociaciones al adoptar sus acuerdos sancionatorios no debe entenderse, no obstante, como la exigencia del principio de tipicidad en materia penal; por

60 STS español en su sentencia 732/2004 del 19 de julio (Sala de los Civil). En esta sentencia, el Tribunal Supremo consideró justificado estimar el recurso interpuesto por el socio expulsado, toda vez que el comportamiento por el cual fue sancionado no estaba previamente tipificado en los estatutos de la asociación. Lo que no impidió que en su FD 1o., el Tribunal reconociera la facultad de autoorganización y funcionamiento interno de las asociaciones sin injerencias públicas y, en consecuencia, la de regular estatutariamente las causas y procedimientos para la expulsión de los socios.

61 Buen Lozano, N. de, Derecho del trabajo, t. segundo, 17a., ed., México, Porrúa, 2003, p. 774 .

D. R. C 2017. UNAM, Instituto de Investigaciones Jurídicas, Boletin Mexicano de Derecho Comparado, núm. 148, pp. 15-48. 
Esta revista forma parte del acervo de la Biblioteca Jurídica Virtual del Instituto de Investigaciones Jurídicas de la UNAM

el contrario, las asociaciones suelen determinar en sus estatutos fórmulas vagas y ambiguas como las de mala conducta, conducta grave, entre muchas otras, dejando un amplio margen a la interpretación de los órganos asociativos, facultad que también corresponde a la asociación en el ejercicio de su autonomía organizacional constitucionalmente protegida.

También creemos que la potestad sancionadora de las asociaciones debe observar el derecho de audiencia del socio inculpado, tal y como lo reconoce también el artículo 371, fr. VII, inciso c), de la LFT, al señalar que el trabajador al que se pretenda expulsar del sindicato deberá ser oído en defensa, y de conformidad con las disposiciones contenidas en los estatutos. La exigencia debería ser aplicable a todo tipo asociativo. Ahora, para que el socio tenga una "garantía de audiencia" dentro del procedimiento sancionador asociativo, resulta necesario que se le informe previamente de los hechos que se le imputan, ${ }^{62}$ si no se le informara no tendría posibilidad de defenderse; una vez informado, se le debería dar un tiempo suficiente para que pueda examinar estos hechos, los antecedentes y la documentación existente y preparar adecuadamente su defensa. En el ejercicio de su defensa, el socio tendrá derecho a presentar las pruebas que considere pertinentes. Si bien la carga de la prueba corresponde a la asociación, ${ }^{63} \mathrm{y}$ al socio le bastará con negar los hechos que se le imputan, éste ha de tener la posibilidad de conocer los elementos de prueba de que dispone la asociación, y puede oponer a los hechos que dan lugar a las medidas disciplinarias, otros hechos que desvirtúen aquéllos, o, sencillamente, la presentación de pruebas que pongan de manifiesto la insuficiencia de las que haya podido presentar la asociación. Cuando así ocurra, ha de darse oportunidad de practicar las pruebas que se estime necesarias. ${ }^{64}$

\section{Ibidem, p. 424.}

63 La presunción de inocencia significa, en el proceso penal, que la carga de la prueba pesa sobre el acusador. Se trata de una presunción iuris tantum, y por tanto admite prueba en contrario. Toda persona a quien se le impute la comisión de un delito ha de presumirse inocente hasta que se pruebe lo contrario. Díez-Picazo, L. M., Sistema de derechos fundamentales, cit., p. 426.

64 En la STS del 6 de marzo de 1992 (Sala de lo Civil), FD 5o., el Tribunal parece negar en un principio que el artículo $24 \mathrm{CE}$, que el socio expulsado considera le ha sido vulnerado, tenga aplicación en las relaciones asociativas, pues este derecho es aplicable más bien en la esfera penal. Pero aun suponiendo, agrega el Tribunal, que estos preceptos tengan su ámbito de aplicación en los procesos civiles sobre derechos fundamentales de los particulares, al examinar el proceso sancionador en contra del socio, se llega a la conclu- 
Esta revista forma parte del acervo de la Biblioteca Jurídica Virtual del Instituto de Investigaciones Jurídicas de la UNAM

\section{$d$. Los acuerdos asociativos para expulsar a sus socios}

Dentro de la misma facultad que tiene la asociación para decidir qué personas han de formar parte ella, tiene la facultad para determinar también quién sale de ella, es decir, para decidir la expulsión de sus miembros. ${ }^{65}$ Ninguna asociación tiene por qué soportar en su seno la presencia de disidentes u opositores empedernidos, ${ }^{66}$ y existe, por lo demás, un valor que merece protección, y que justifica también la expulsión de los socios, que es la unidad y la estabilidad del grupo. ${ }^{67}$

Ahora bien, la expulsión de un socio puede obedecer a dos circunstancias; la primera a una sanción, cuando el socio haya incurrido en alguna de las conductas prohibidas por el mismo ente en sus estatutos, en cuyo caso estará ejerciendo su potestad disciplinaria; y la segunda se refiere al ejercicio de la libertad negativa de asociación que tiene el ente, y que en el ejercicio de este derecho decide no seguir asociado con uno de sus miembros; o sea, así como un socio ejerciendo su derecho de asociación en sentido negativo decide abandonar la asociación, ésta también tiene el derecho de decidir voluntaria y unilateralmente dejar de estar asociada con uno de sus miembros, y por ello decide expulsarlo. En este sentido, la sentencia 218/1988 del 22 de noviembre, del Tribunal Constitucional de España, reconoció que el derecho de asociación "se extiende con toda evidencia a regular en los estatutos las causas y procedimientos de la expulsión de los socios", ${ }^{68}$ causas que, según entendemos nosotros, no tienen que obedecer forzosamente a cuestiones sancionadoras; en el derecho de sociedades, por ejemplo, la expulsión de los socios no se entiende como una sanción, sino como un derecho de defensa ejercido colectivamente por los socios, fieles al fin común, para asegurar la consecución del mismo

sión de que tuvo plena ocasión de defenderse, tanto en el expediente disciplinario que se le siguió por la entidad como a lo largo de todo el procedimiento judicial.

65 Anzures Gurría, J. J., La protección constitucional de las asociaciones... cit., pp. 417 y ss.

66 Marín López, J. J., "Comentario a la sentencia de 24 de marzo de 1992", CCFC, núm. 28, 1992, p. 301 .

67 Idem.

68 También la STS 732/2004 del 19 de julio (Sala de los Civil) en su FD 1o., recuerda que el derecho de asociación, protegido por los artículos 22 y 53, CE, comprende, entre otros, la facultad de organizar y determinar el funcionamiento interno de las asociaciones sin injerencias públicas y, por ello, la de regular estatutariamente las causas y procedimiento para la expulsión de los socios. 
Esta revista forma parte del acervo de la Biblioteca Jurídica Virtual del Instituto de Investigaciones Jurídicas de la UNAM

frente a las perturbaciones originadas por la conducta o las circunstancias concurrentes en uno o varios socios. ${ }^{69}$

Los acuerdos de expulsión suelen colisionar con el derecho de permanencia de los socios dentro de la asociación. El conflicto existente entre el derecho de expulsión de las asociaciones y el derecho de permanencia de los socios constituye la colisión del mismo derecho fundamental de asociación en dos dimensiones distintas, ejercido por dos personas diferentes. Por un lado la asociación en el ejercicio de la dimensión colectiva del derecho de asociación, que comprende la facultad de autoorganizarse, y en este sentido, de determinar y adoptar las causas y procedimientos de expulsión de sus socios; y por otro lado, el del socio ejerciendo el mismo derecho en sentido individual positivo, que comprende el derecho de permanecer en el ente del que forma parte.

En España, la doctrina jurisprudencial sustentada por el Tribunal Constitucional a partir de su sentencia 218/1988 del 22 de noviembre, ${ }^{70}$

69 Pérez Escalona, S., La asociación y el derecho de sociedades, cit., p. 239. Véase también Alfaro Águila-Real, J., "Conflictos intrasocietarios", Revista de Derecho Mercantil, núm. 222, 1996, pp. 1104 y 1120

70 En España, el leading case en este tipo de conflictos lo constituye la ya citada STC 218/1988 del 22 de noviembre. En este caso, la asociación "Círculo Mercantil", un casino de la ciudad de la Línea de la Concepción, en Cádiz, en el ejercicio de su facultad autoorganizativa, acordó expulsar a tres de sus miembros por considerar que habían cometido una "falta grave" de acuerdo con lo establecido en sus propios estatutos. Los expulsados recurrieron la decisión de la Asociación ante el juzgado de distrito, que dictó sentencia desestimatoria, misma que fue apelada ante la Audiencia Provincial de Cádiz, que consideró estimada la demanda original y condenó a la asociación a readmitir a los socios. Ante esta resolución, la asociación interpuso un recurso de amparo ante el Tribunal Constitucional entendiendo que se había vulnerado su derecho fundamental de asociación, en tanto su facultad autoorganizativa. El Tribunal Constitucional admitió el recurso y reconoció en su sentencia que efectivamente, el derecho fundamental de asociación comprende el derecho de autoorganización del ente, y que en el ejercicio de este derecho, la asociación puede regular las causas y procedimientos de expulsión de sus socios, y en este caso, el acuerdo de expulsión había sido válidamente adoptado, conforme a sus propios estatutos y de acuerdo con las leyes. Precisamente el problema que se presentó en este caso fue que el acuerdo asociativo de expulsión impugnado por los socios no fue contrario a los estatutos de la asociación ni a las leyes, pero a consideración de los socios afectados la interpretación que de ellos hizo el órgano rector de la asociación fue errónea. Por esta razón, el Tribunal Constitucional, respetando el derecho de autoorganización de las asociaciones, determinó que la intervención judicial "no consiste en que el Juez pueda entrar a valorar, con independencia del juicio que ya han realizado los órganos de la asociación, la conducta del socio, sino en comprobar si existió una «base razonable» para que los órganos de las 
Esta revista forma parte del acervo de la Biblioteca Jurídica Virtual del Instituto de Investigaciones Jurídicas de la UNAM www.juridicas.unam.mx

marca las pautas de solución para este tipo de conflictos entre asociación y socio, decantándose por un papel preponderante del derecho de autoorganización de las asociaciones, principalmente en dos sentidos: por un lado, reconociendo que las asociaciones, en el ejercicio de su facultad autoorganizativa, tienen la facultad de establecer en sus estatutos los procedimientos y causas de expulsión de sus socios, y con base en ellos adoptar los acuerdos conducentes a su exclusión; y por otro lado, sostiene que la intervención del juez no puede consistir en "entrar a valorar, con independencia del juicio que ya han realizado los órganos de la asociación, la conducta del socio, sino en comprobar si existió un «base razonable» para que los órganos de las asociaciones tomasen la correspondiente decisión".

Lo que ha de quedar claro es que aunque no todo acto de expulsión obedece a una sanción, la facultad de expulsión de una asociación no puede hacerse ad nutum, sino observando al menos un mínimo de principio de legalidad; es decir, unas causas previamente establecidas en los estatutos (aunque no obedezcan a conductas sancionables), y en caso de que no se contemplara causa alguna, creemos que la asociación sí tiene la facultad de expulsar a sus miembros cuando la causa sea justificada y se funde y motive correctamente, para evitar cualquier acto de arbitrariedad por parte de la asociación. ${ }^{71}$

\section{EL DERECHO DE LA ASOCIACIÓN A DEJAR DE EXISTIR}

Por último, entendemos que forma parte también de la facultad de autoorganización de la asociación la potestad para determinar libremente y sin interferencia de terceros, dejar de existir. Es lógico que si una asociación tiene derecho a existir y funcionar libremente, esta facultad comprenda también el cómo y cuándo dejar de hacerlo; o, dicho de otra forma, sería ilógico

asociaciones tomasen la correspondiente decisión"; y con base en este razonamiento anuló la sentencia de la Audiencia Provincial y concedió el amparo a la asociación.

71 Como constató el Tribunal Supremo en su sentencia 169/1999 del 2 de marzo (Sala de lo Civil), en el que el acuerdo de expulsión adoptado por la asociación "Real Aeroclub de Vigo" respecto de unos socios, fue un acto indebido, sin causa acreditada y por mera represalia. También en su sentencia del 24 de marzo de 1992 (Sala de lo Civil), el Tribunal Supremo reconoció que la permanencia o vinculación de los socios con la asociación no puede depender de la voluntad excesiva de la junta directiva que resuelve "ad hoc", según la valoración del caso". En el mismo sentido, la STS 122/1998 del 28 de diciembre (Sala de lo Civil), FD 10. 
Esta revista forma parte del acervo de la Biblioteca Jurídica Virtual del Instituto de Investigaciones Jurídicas de la UNAM

que, constituida una asociación estuviera obligada a existir por siempre en contra de su voluntad y de la voluntad de los miembros que la componen. El derecho de existir ha de comprender el de dejar de existir. Se trata, pues, de la vertiente negativa de la libertad de autoorganzación de la asociación.

Este derecho a dejar de existir suele denominarse en el derecho de sociedades como disolución, la cual puede darse por distintos factores; uno de ellos, porque así lo determine la ley. La determinación por ley de la disolución de una asociación no debe entenderse como una violación a la libertad de la asociación para decidir libremente sobre su disolución, sino como un requisito legal que la ley reguladora de su tipo impone a las asociaciones que regula; por ejemplo, si el capital social de una sociedad mercantil se reduce por debajo del mínimo legal, la asociación debe disolverse.

Otro caso común de disolución asociativa es el transcurso del tiempo para el cual la asociación fue constituida. Este plazo puede fijarse por ley, en cuyo caso la asociación puede continuar con su existencia, aunque ya no será el tipo asociativo regulado por esta norma. Si el transcurso del tiempo está determinado en los estatutos, cumplir con el plazo no es más que el cumplimiento de la voluntad asociativa, ya que fue la asociación (o en su caso los socios fundadores) la que al redactar los estatutos determinó libremente su tiempo de existencia.

Otra posibilidad sería que la asociación, mediante el acuerdo correspondiente, tomado por el órgano competente para ello y de acuerdo con las condiciones estatutariamente establecidas, determinara libremente su disolución. La asociación, en tanto persona, tiene la capacidad de decidir imponiendo su voluntad a todos los socios, de modo que si determina su disolución anticipada, implica que el periodo señalado para actuar se reduce en tiempo, y la sociedad se liquida, y basta la expresión del ente en este sentido para que surta sus efectos, entendiendo que los estatutos se modifican por lo que se refiere al término; esto puede ocurrir, por ejemplo, por la imposibilidad material de alcanzar los fines por los cuales la asociación fue constituida. Ya por último, entendemos que en el ejercicio de su libertad para dejar de existir, la asociación puede dejar de existir tal y como es y cambiar, crecer o reducirse; por esto también forma parte de la libertad de autoorganización la decisión de fusionarse o escindirse con otras asociaciones. ${ }^{72}$

72 Véase el artículo 232, LGSM, y el artículo 2720, CG. 
Esta revista forma parte del acervo de la Biblioteca Jurídica Virtual del Instituto de Investigaciones Jurídicas de la UNAM

\section{CONCLUSIONES}

La facultad de autoorganización de las asociaciones se encuentra protegida por el artículo 9o., CPEUM, y se refiere a la capacidad del ente para existir y funcionar libremente sin interferencia alguna por parte de terceros. El derecho a existir no es tanto un derecho de la asociación, sino de los socios que crean la asociación para que ésta sea reconocida por el derecho desde el primer momento en que se constituye, momento que ocurre con la concurrencia de la voluntad de las partes. Desde este instante, entendemos que una asociación nace con personalidad jurídica, y desde este momento se encuentra constitucionalmente protegida por el mismo derecho fundamental de asociación.

El derecho de la asociación a funcionar libremente sin interferencia alguna por parte de terceros se refiere a la facultad para darse sus propios estatutos (siempre que no sean contrarios a las leyes ni a la Constitución) y para adoptar sus acuerdos asociativos. Estos últimos se refieren únicamente a cuestiones de autoorganización, pues es lógico que no todo acuerdo asociativo se encuentra protegido por el derecho fundamental de asociación. Entonces, el ámbito de actuación de la asociación constitucionalmente protegido por el derecho fundamental de asociación se refiere a la facultad de la asociación para adoptar todos aquellos acuerdos tendentes a determinar la estructura y organización interna de la asociación, tanto aquellos que tienen que ver con sus órganos y su estructura como los que tienen que ver con sus miembros.

La facultad de la asociación para decidir sobre sus miembros se extiende con toda evidencia a regular en sus estatutos los requisitos de ingreso de nuevos miembros, las causas y procedimientos de expulsión de socios, así como el régimen disciplinario interno. La facultad de la asociación para decidir sobre el ingreso de nuevos miembros no colisiona con el derecho de ingreso de las personas, pues este último es un derecho que se ostenta frente al poder del Estado y no frente a la asociación a la que se pretende ingresar. La potestad disciplinaria de la asociación se verá limitada por la observancia de un mínimo de legalidad y seguridad jurídica de sus miembros, de tal forma que si bien la asociación tiene la facultad para sancionar a sus miembros, esta potestad no puede realizarse ad nutum. De igual forma, el acuerdo asociativo de expulsión de socios habrá de obser- 
Esta revista forma parte del acervo de la Biblioteca Jurídica Virtual del Instituto de Investigaciones Jurídicas de la UNAM

var una razón justificada y no podrá realizarse por el mero capricho de la asociación.

Por último, cabe señalar que el alcance del derecho de autoorganización de las asociaciones vendrá determinado por la naturaleza de cada tipo asociativo. Así, una asociación estrictamente privada que no goza de financiación pública, que se sostiene con ingresos propios o procedentes de particulares, que ejercite actividades puramente privadas y que persigue como objetivo la satisfacción de necesidades puramente privadas, gozará de un ámbito de autonomía sumamente amplio al adoptar sus distintos acuerdos asociativos. ${ }^{73}$ Cuando se trate de asociaciones de relevancia pública a través de las cuales se garantiza el mantenimiento y consolidación del Estado democrático, como es el caso de los partidos políticos y los sindicatos, su autonomía se verá limitada por los objetivos que a través de ellas el Estado pretenda alcanzar o garantizar para toda la ciudadanía, y si las asociaciones privadas ostentan de hecho o de derecho una posición dominante o monopolista en algún campo, de manera que la pertenencia o exclusión de ellas supusiera un perjuicio para el particular afectado, la asociación verá también limitado su derecho de autoorganización. Lo mismo ocurre con las asociaciones que exploten algún recurso público o que tengan la concesión administrativa de un servicio público.

\section{BibliografíA}

Alfaro Águila-REAL, J., "Autonomía privada y derechos fundamentales", $A D C, 1993$.

, "Libertad e igualdad en el derecho de asociación", Los alardes: una perspectiva jurídica. Libertad e igualdad en las relaciones entre particulares, Irún, Casino de Irún, 2000.

Alonso Olea, M., Derecho del trabajo, 9a. ed., Madrid, Servicio de Publicaciones de la Universidad Complutense, 1985.

Álvarez Conde, E. (ed.), "La exigencia de democracia sindical en la Constitución y en la normativa de desarrollo", en AAVV, Diez años de régimen constitucional, Madrid, Tecnos, 1989.

ANZURES GURRÍA, J. J., La protección constitucional de las asociaciones. Sobre la dimensión colectiva del derecho de asociación, Madrid, CEPCM, 2014.

73 Marín López, J. J., El derecho de ingreso en las asociaciones..., cit., p. 22. 
Esta revista forma parte del acervo de la Biblioteca Jurídica Virtual del Instituto de Investigaciones Jurídicas de la UNAM

BARRERA Graf, J., Instituciones de derecho mercantil (generalidades, derecho de la empresa, sociedades), México, Porrúa, 2000.

Bermejo Vera, J., "La dimensión constitucional del derecho de asociación", RAP, núm. 136, 1995.

BETEGÓn CARRillo et al. (coords.), "Artículo 22 de la Constitución española", Constitución y derechos fundamentales, 2004.

BilbaO Ubillos, J. M., "Prohibición de discriminación y autonomía privada", Los alardes: una perspectiva jurídica. Libertad e igualdad en las relaciones entre particulares, Irún, Casino de Irún, 2000.

— Libertad de asociación y derechos de los socios, Universidad de Valladolid, 1997.

, "Las garantías de los artículos 24 y 25 de la Constitución en los procedimientos disciplinarios privados. Un análisis de su posible aplicación a las sanciones impuestas por los órganos de gobierno de las asociaciones", Derecho Privado y Constitución, núm. 9, 1996.

- La eficacia de los derechos fundamentales frente a particulares. Análisis de la jurisprudencia del Tribunal Constitucional, Madrid, Centro de Estudios Políticos y Constitucionales, 1997.

Buen Lozano, Néstor de, Derecho del trabajo, t. II, 17a. ed., México, Porrúa, 2003.

Cueva, M. de la, El nuevo derecho mexicano del trabajo, t. II, 12a. ed., México, Porrúa, 2002.

DíEz-Picazo, L. M., Sistema de derechos fundamentales, 3a. ed., Aranzadi, 2008.

Fernández SEgado, F., Las Constituciones históricas españolas. Un análisis histórico-jurídico, Madrid, Civitas, 1986.

Ferrara, F., Teoría de las personas jurídicas, Granada, Comares, 2006.

Ferrer I. Riba y SALVADOR CODERCH, P., Asociaciones, derechos fundamentales y autonomía privada, Madrid, Civitas, 1997.

Gastroph, C., Die politischen Vereinigungen. Inhalt und Grenzen der Vereinigungsfreiheit des Art. 9 des Grundgesetzes im politischen Bereich in der Verfassungsstruktur der Bundesrepublik Deutschland, Berlín, Dunker \& Humblot, 1970.

Gómez Montoro, A. J., Asociación, Constitución, ley. Sobre el contenido constitucional del derecho de asociación, Madrid, Centro de Estudios Políticos y Constitucionales, 2004.

, "La titularidad de derechos fundamentales por personas jurídicas. Un intento de fundamentación", REDC, año 22, núm. 65, 2002. 
Esta revista forma parte del acervo de la Biblioteca Jurídica Virtual del Instituto de Investigaciones Jurídicas de la UNAM

Hesse, K., Grundzüge des Verfassungsrechts der Bundesrepublik Deutschland, Heildelberg, G. F. Müller, 1999.

JARASS, H. D., "Art. 9o., Vereinigungs- und Koalitionfreiheit", en JARASS, H. D., und Pieroth, B., Grundgesetz für die Bundesrepublik Deutschland, Kommentar, München, Verlag C. H. Beck, 2007.

KLUTH, W., "Artikel 9, Vereinigungs-und Koalitionsfreiheit", en FRIAUFHöfling (Hrsg.), Berliner Kommentar zum Grundgesetz, Lfg., Dezember, 2009.

López-Nieto y Mallo, F., La ordenación legal de las asociaciones, 4a. ed., Madrid, Dykinson, 2004.

Lucas Murillo de la Cueva, E., El derecho de asociación, Madrid, Tecnos, 1996.

, Igualdad y autonomía. Las competencias sobre asociaciones en la jurisprudencia constitucional, Madrid, Civitas, 1999.

MAGRINI, S., "Il sindacato come soggetto", Indagine sul sindacato, a cura dell'ISLE, Milán, Giuffrè, 1970.

MARín López, J. J., "Comentario a la sentencia de 24 de marzo de 1992”, Cuadernos Civitas de Jurisprudencia Civil, núm. 28, 1992.

"La intervención judicial en los conflictos endoasociativos. El caso de la expulsión de asociados", Poder fudicial, núm. 14, 1989.

, "El derecho de ingreso en las asociaciones", Los alardes: una perspectiva jurídica. Libertad e igualdad en las relaciones entre particulares, Irún, Casino de Irún, 2000.

Merten, D., "Vereinsfreiheit", en Isensee, J. y KirchHof, P., Handbuch des Staatsrechts der Bundesrepublik Deutschland, Band VII Freiheitsrechte, Heidelberg, C. F. Müller Verlag, 2009.

NipPeRdey, H. C., Grundrechte und Privatrecht, Verlag, Scherpe, 1961.

, "Gleicher Lohn der Fraufür gleiche Leistung", Recht der Arbeit, München, núm, 4, abril 1950.

, "Freie Entfaltung der Persönlichkeit", en Bettermann, H. C. Nipperdey y Scheuner, U., Die Grundrechte. Handbuch der Theorie und Praxis der Grundrechte, t. IV, 2, Berlín, Duncker \& Humblot, 1962.

Orozco Henríquez, J. J., "Artículo 9o.", Constitución Política de los Estados Unidos Mexicanos comentada, 5a. ed., México, UNAM, Instituto de Investigaciones Jurídicas, 1994.

PACE, A., "Comentario al artículo 18 CI", en BRANCA, G. (dir.), Comentario della Constituzione. Artículo 13-20, Bolonia-Roma, 1977. 
Esta revista forma parte del acervo de la Biblioteca Jurídica Virtual del Instituto de Investigaciones Jurídicas de la UNAM

Pelayo Olmedo, J. D., "El derecho de asociación en la historia constitucional española, con particular referencia a las leyes de 1887 y 1964", Historia Constitucional (revista electrónica), núm. 8, 2007.

REY MARTínez, F., El derecho fundamental a no ser discriminado por razón de sexo, Madrid, McGraw-Hill, 1995.

PÉRez Escalona, S., La asociación y el derecho de sociedades. Una revisión en clave contractual, Madrid, Civitas, 2007.

SALVADOR CODERCH, P. (coord.), Asociaciones, derechos fundamentales y autonomía privada, Madrid, 1997.

Sánchez Galero, F., Instituciones de derecho mercantil, 14a. ed., Madrid, Revista de Derecho Privado, 1990.

Sauca Cano, J. M., La ciencia de la asociación de Tocqueville. Presupuestos metodológicos para una teoría de la vertebración social, Madrid, Centro de Estudios Constitucionales, 1996.

— , "Artículo 22 de la Constitución española: el derecho de asociación”, en Bretegón CARrillo, F. J. et al., Constitución y derechos fundamentales, Madrid, Presidencia del Gobierno, 2004.

SchmidT, T., Die Freiheit verfassungswidriger Parteien und Vereinigungen. Zur Schrankenlehre im Rahmen von Art. 21 Abs. 2 und Art. 9 Abs. 2 GG, Berlín, Dunker und Humbolt, 1983.

SChNORR, G., Öffentliches Vereinsrecht, Kommentar zum Vereinsgesetz, Verlag, 1965.

ScHOLZ, R., Koalitionsfreiheit als Verfassungsproblem, München, Beck, 1971.

Velloso Jiménez, M. L., "Los orígenes constitucionales del derecho de asociación en España (1868-1923)", Anuario de la Facultad de Derecho, núm. 1, 1982.

Wilhelm Oertmann, P. E., "Die rechtliche Natur der Vereinssatzung", ArchRWiPhil, 7 (1913/14). 